\title{
FREUD E GRADIVA: CONCEITOS PSICANALÍTICOS DELINEADOS A PARTIR DA ANÁLISE DE UM ROMANCE \\ Anaxianne W. N. Vieira ${ }^{8}$
}

\section{Resumo}

Neste trabalho analisamos extensamente o primeiro escrito de Sigmund Freud sobre uma obra literária, intitulado "Delírios e sonhos na Gradiva de Jensen", realizado no ano de 1907. Estabelecemos conexões entre tal análise e a teoria psicanalítica que, na primeira década do século XX, encontrava-se em fase de formulação de conceitos cruciais, tais como o de fantasia. Discorremos através do método de análise bibliográfica, sobre a influência que a arte literária exerceu em Freud e sobre como esta alcançou o desenvolvimento da psicanálise durante toda a vida de seu criador.

Palavras-Chave: Psicanálise; literatura; fantasia; ficção.

\section{FREUD AND GRADIVA: PSYCHOANALYTIC CONCEPTS OUTLINED FROM THE ANALYSIS OF A ROMANCE}

\begin{abstract}
In this paper we widely analyze the first Sigmund Freud's works about a literary work entitled "Der Wahn und die Träume in W. Jensens Gradiva", held in the year 1907. We establish connections between this analysis and the psychoanalytic theory that in the first decade of the twentieth century was under the formulation of key concepts such as fantasy. Through the literature review method we discus on the influence that the literary art exerted on Freud's works and how this reached the development of psychoanalysis throughout the life of its creator.
\end{abstract}

Keywords: Psychoanalysis; literature; fantasy; fiction.

\section{Introdução}

No ano de 1907, Freud publicou a primeira análise feita por ele de uma obra literária. Tratava-se da análise do romance Gradiva - uma fantasia pompeiana, publicada originalmente em 1903, pelo escritor alemão Wilhelm Jensen. Na verdade, foi Jung quem chamou a atenção de Freud para esta obra. Segundo consta na nota do editor inglês da edição Standart das Obras Completas de Freud, acredita-se que o mesmo empreendeu tal análise como uma espécie de agrado a Jung, que ele viria a conhecer pessoalmente meses depois.

Sigmund Freud possuía uma atração realmente fascinante pelas criações artísticas, em especial, pela literatura e pela escultura. Pensava ele, quando sua teoria já se encontrava relativamente desenvolvida, que o artista sabia antecipadamente de algo que escapava à psicanálise. Assim sendo, construção da teoria freudiana foi acompanhada passo a passo pelos olhos desta arte, e delineada especialmente por obras-primas que grandes autores como Shakespeare, Goethe, Cervantes, Balzac - preferências freudianas e tantos outros nos deixaram.

É bem verdade que era importante para Freud o reconhecimento de sua teoria como ciência. Contudo, Freud se debruçou sobre a literatura por uma preferência pessoal, o que explica sua busca incessante de respostas neste campo. A intensa investigação pelo saber inconsciente e sobre as formas de mobilização subjetiva incitaram-

\footnotetext{
${ }^{8}$ Mestre em Psicologia pela Universidade Federal do Ceará (2009).
} 
no a procurar em outras fontes, que não as do saber científico de seu tempo, as respostas para o que supostamente tinha sido negligenciado até então.

\section{Metodologia}

A metodologia utilizada foi a análise interpretativa do texto Delírios e sonhos na Gradiva de Jensen, o exame minuciosamente realizado por Freud do romance do escritor alemão. Demonstramos a relação com alguns conceitos cruciais para psicanálise, tais como o de fantasia e pulsão. Utilizamos como base o referido escrito do psicanalista e consultamos as formulações sobre a teoria freudiana realizadas por ele mesmo até então.

\section{Resultados e Discussão}

Na primeira parte de Delírios e sonhos na Gradiva de Jensen, Freud (1907) descreve e explica a trama para os leitores. A narrativa de Gradiva por ele feita destina-se, sobretudo, àqueles que não conhecem a dita obra de Wilhelm Jensen. Além disso, Freud empreende comentários sobre as personagens e suas ações dramáticas. O primeiro capítulo de seu trabalho é, pois, uma introdução às considerações que estariam por vir.

Gradiva: uma fantasia pompeiana é a história de um arqueólogo chamado Norbert Hanold, que descobre num museu italiano um baixo-relevo que o intriga e fascina. Este baixo relevo é de uma jovem que parece caminhar e, ao andar, levanta ligeiramente a túnica, que faz com que seus pés calçados com sandálias sejam descobertos, mostrando que um deles está em posição vertical. Norbert faz uma cópia em gesso e chama-lhe "Gradiva", que segundo ele significa "aquela que resplandece ao andar". E o rapaz, que até então mostrava desinteresse pelas mulheres reais, vive agora obcecado com uma figura hipotética que viveu e morreu há séculos. Utilizando-se de seus conhecimentos arqueológicos, ele tece toda uma trama fantasiosa sobre "a jovem que avança".

Logo em seguida, o arqueólogo tem um terrível pesadelo. Estava ele em Pompéia (cidade soterrada pelo vulcão Vesúvio) no dia de sua tragédia, e lá via Gradiva. Com isso, Norbert conclui que a jovem é uma pompeiana e que vivia, segundo o mesmo, "na mesma época que ele, sem que disso ele tivesse a menor suspeita". No momento em que o caos abala a cidade, o arqueólogo grita em socorro da moça, mas Gradiva permanece andando em direção a uma escada, onde senta em seus degraus e permanece com a cabeça inclinada para baixo enquanto sua face se empalidece, parecendo transformar-se em mármore, com uma expressão tranquila, como se estivesse adormecida, até que a chuva de cinzas lhe cobre completamente.

Ao acordar, o herói do romance sente como se estivesse na Pompeia do ano de 79 d.C. devido aos barulhos que ecoavam em seus ouvidos. Mas logo percebe que, na verdade, os gritos vinham da cidade que borbulhava do lado fora de sua casa. Vai até a janela e tem a impressão de reconhecer Gradiva andando. Sai correndo para encontrá-la, mas as risadas dos passantes (que o viam com roupas de dormir) fazem com que ele volte a si e à casa.

Depois disso, ele decide viajar até a Itália, e assim chega em Pompeia. Novamente, ele vê a mesma Gradiva sair de uma casa e atravessar a rua como em seu sonho. De súbito, vai em sua direção e faz-lhe perguntas em grego, ao que a jovem lhe diz: "Se o senhor quiser conversar comigo, tem que falar alemão".

A partir daí, a trama se desenvolve até o ponto em que descobrimos que Gradiva era, na verdade, uma garota alemã real chamada Zoe Bertgang, e esta era amiga de infância de Norbert Hanold (um amor de infância, supõe Freud), há muito por ele esquecida. A moça embarcara no delírio do arqueólogo, fazendo-se passar pela Gradiva que por ele fora imaginada, e com isso empreende, inadvertidamente, uma espécie de "tratamento", que culmina na "cura" do delírio do herói. 
Após a descrição do conteúdo do romance, percebemos certa maneira de conduzir a análise da obra que se mostra bastante semelhante ao modo como o Freud descreveu o relato de grande parte dos sonhos descritos em sua Interpretação dos Sonhos (1900). Vemos isto se apresentar da seguinte forma: há um relato da história, seguida de uma pormenorizada explicação dos fatores que são aqueles que, provavelmente, levaram à sequência dos acontecimentos (segundo, inclusive, a lógica atemporal do inconsciente). E, mais ainda, não só há considerações sobre as personagens da história feitas durante o relato, mas também existem reflexões acerca da própria teoria psicanalítica. Assim, Freud mantém o seu leitor sempre atento às conexões por ele percebidas entre a obra de arte analisada e sua própria teoria.

Algo aludido logo nas primeiras páginas da análise freudiana de Gradiva (bem como ao longo de todo seu escrito) é a questão que aponta para os sonhos. Trata-se da discussão que se refere ao rechaço da ciência com relação à ideia de que sonhos possuem um sentido e que são realizações de desejos (e Freud retornava constantemente à sua Interpretação dos Sonhos para ratificar esta afirmação). Como contraponto, afirmava ele colocar-se ao lado da "superstição", apesar das reprovações da ciência (Freud, 1907 p. 19), já que esta afirma que o sonhar era um processo eminentemente fisiológico, não carecendo procurar nenhum sentido "oculto" em seu conteúdo.

Neste momento de sua elaboração (Freud, 1907), surge a relação feita entre o sonhar e a criação artística (especificamente, neste momento, a literária), bem como há a introdução da ideia de que os escritores possuem o dom de captar algo da subjetividade humana que lhes é particular, e do qual a "ciência comum" não é capaz de compartilhar. Escreve ele: “(...) Pois quando um autor faz sonhar os personagens construídos por sua imaginação, segue a experiência cotidiana de que os pensamentos e os sentimentos das pessoas têm prosseguimento nos sonhos (...) $\mathrm{E}$ os escritores criativos são aliados muito valiosos, cujo testemunho deve ser levado em alta conta, pois costumam conhecer toda uma vasta gama de coisas entre o céu e a terra com os quais a nossa filosofia não nos deixou sonhar. Estão bem adiante de nós, gente comum, no conhecimento da mente, já que se nutrem em fontes que ainda não tornamos acessíveis à ciência" (Freud, 1907 p. 20).

Segue-se, então, a já mencionada narração do texto feita por Freud, recheada de sutis alusões à teoria sobre o funcionamento do aparelho psíquico em pequenas notas e destaques em itálico.

O que vemos em seu texto é a personagem principal, o arqueólogo Norbert Hanold, sendo "posto em análise". Em outras palavras, o mesmo sendo claramente utilizado por Freud (1907) como parâmetro demonstrativo de sua teoria (arriscamo-nos inclusive a dizer, como um "experimento"), até aquele momento do seu desenvolvimento, como na passagem onde ele falará, pela primeira vez, sobre o segundo sonho do arqueólogo: "Afinal, ele se recolheu e teve um sonho singularmente absurdo, embora sem dúvida provocado pelas experiências do dia" (Freud, 1907 p. 32).

Tais ideias, tanto a do absurdo dos sonhos quanto a de os mesmos serem influenciados por experiências da vida de vigília, especialmente as do dia anterior ao sonho, já haviam sido amplamente desenvolvidas anteriormente, e podem ser encontradas em sua Interpretação dos Sonhos.

Num determinado momento da narrativa freudiana, outro conceito psicanalítico é claramente delineado. Trata-se da passagem onde Freud pede para considerar o momento em que Zoe-Gradiva indaga Norbert Hanold se ele não se lembra de já ter compartilhado com ela uma refeição há dois mil anos atrás. Freud, que delegou abertamente à Gradiva o papel daquela que é responsável pela "cura" dos delírios do herói (sua "analista", nesse sentido), detecta, nesta indagação, uma espécie de eco de lembranças infantis já esquecidas: "Assim sendo, não se trata de produtos arbitrários de sua imaginação, tendo sido essas fantasias determinadas sem que ele soubesse disso, pelo acervo de impressões infantis esquecidas, mas nele atuantes" (Freud, 1907 p. 37). Para Freud, o autor parece explicitar de forma nítida o que, em psicopatologia, levaria o nome de recalque. Tais esquecimentos de lembranças infantis são justamente aquilo que o próprio Freud considerará futuramente em "A história do movimento psicanalítico" (Freud, 1914), como a "pedra angular" da psicanálise: "A teoria da repressão é a pedra angular sobre a qual repousa toda a estrutura da psicanálise. É a parte mais essencial dela e todavia nada mais é senão a 
formulação teórica de um fenômeno que pode ser observado quantas vezes se desejar se se empreende a análise de um neurótico sem recorrer à hipnose. Em tais casos encontra-se uma resistência que se opõe ao trabalho da análise e, a fim de frustrá-lo, alega falha de memória (Freud, 1914 p. 26).

Prosseguindo, Freud continua a explicar o funcionamento deste mecanismo, esclarecendo que o recalque não implica numa extinção da memória. Ao contrário: sob a influência de um fator externo, o que é recalcado é capaz de retornar às lembranças, causando "consequências psíquicas que podem ser consideradas como produtos da modificação da lembrança esquecida" (Freud, 1907 p. 39). De fato, a história do romance parece mostrar-se um belo exemplar dos mais importantes conceitos psicanalíticos.

Na segunda parte de seu trabalho de análise, Freud dá-se conta de que seu propósito inicial era analisar os sonhos do herói que aparecem no romance. Contudo, percebe que havia ido além do que planejava, dissecando a história por completo, à luz dos conceitos psicanalíticos. Afirma, porém, que "Na verdade, todo esse trabalho não foi inútil" (Freud, 1907 p. 45). E, de fato, não foi. Com sua análise pormenorizada da obra de Jensen, tivemos acesso a uma das mais belas contribuições das artes à psicanálise, captadas por aquele que foi o seu fundador.

Freud, a partir de então, explica aos seus leitores o fato de ter tratado as manifestações psíquicas das personagens como se estas fossem pessoas presentes na "realidade empírica", reais, e não personagens de ficção. Segundo ele, as descrições utilizadas pelo autor são (ainda que sua história tenha sido classificada pelo próprio como "fantasia") fielmente correspondentes à realidade, o que faz com que o psicanalista tome Gradiva como um estudo psiquiátrico. Novamente, percebe-se que Freud aproxima a arte literária com a "ciência" (ou pelo menos, sua ciência), já que realiza suas considerações tal como se tratasse de um caso clínico. Na verdade, confirma-se a já mencionada aproximação feita por Freud entre psicanálise e literatura, notada a partir da semelhança entre o relato da história, das tramas psíquicas que envolvem Norbert Hanold e Zoe-Gradiva e o relato de casos clínicos.

Notamos neste ponto outra ideia advinda originalmente dos estudos psicanalíticos presentes neste texto: a de que é tênue a linha que separa o normal do patológico. Porém, de forma bem sutil. Ao falar dos estados graves de afecções mentais, o psicanalista ousa afirmar que "Na verdade, só através deles é que se pode chegar à compreensão dos estados normais, assim como dos fenômenos das doenças graves" (Freud, 1907 p. 47).

Ainda no segundo capítulo, Freud faz uma análise detalhada do primeiro sonho da personagem principal do romance, recorrendo inúmeras vezes, como já foi mencionado, à sua Interpretação dos Sonhos. Os mecanismos descritos, as peculiares formas de disfarce do conteúdo latente, os desejos e fantasias, tudo isto foi cuidadosamente analisado por ele. Mais uma vez, o vemos utilizando sua teoria para a explicação de mecanismos presentes no texto, mas que bem poderiam ser tomados como sendo pertencentes à realidade. Neste ponto, Freud se pergunta se o autor observou todas as regras (ou melhor, as suas regras) do funcionamento psíquico dos sonhos, ou seja, se ele escreveu as linhas de seu romance baseado na ciência freudiana ainda em formação, pois as descrições são totalmente fiéis à realidade psíquica tal como ele a desenvolveu com ideia. Sabemos, entretanto, através de cartas trocadas entre ele e o autor alemão anos mais tarde, que Jensen dissera a Freud que não: ele não possuía ciência de seus escritos sobre os sonhos ou qualquer mecanismo explicado pela psicanálise. Todo o conteúdo de sua obra tinha partido única e exclusivamente de sua mente criativa.

Foi em sua análise de Gradiva onde Freud percebeu que o artista (particularmente, no caso, os escritores criativos) captava algo que aos "cientistas da alma" era mais penoso "recolher", delegando ao artista uma espécie de poder que a maioria das pessoas da época, bem como as de hoje, considerariam como um absurdo. Os escritores seriam, pois, os verdadeiros "psicólogos", capazes de compreender a subjetividade humana. Para ele, a arte viria, neste sentido, antes da ciência, sendo sua precursora: "Dizem que um autor deveria evitar qualquer contato com a psiquiatria e deixar aos médicos a descrição de estados mentais patológicos. A verdade, porém, é que o escritor 
verdadeiramente criativo jamais obedece a essa injunção. A descrição da mente humana é, na realidade, seu campo mais legítimo: desde tempos imemoriais, ele tem sido um precursor da ciência e, portanto, da psicologia científica" (Freud, 1907 p. 47).

Desta forma, ele explica que seria um erro da psiquiatria desconsiderar as contribuições de outras áreas, restringindo ao seu campo os estudos das doenças psíquicas graves. Também acredita que o escritor não deve esquivar-se de considerar a ciência para elaborar suas criações.

Destarte, é neste mesmo trabalho onde averiguamos que o psicanalista demonstra, ainda que de forma extremamente sutil, certa admiração pela capacidade de captação do escritor (ou melhor, do artista). Surpreendeuse com como uma obra literária, publicada em 1903, tinha sido capaz de basear sua criação naquilo que ele próprio, como médico, havia pesquisado arduamente por um longo período. Disse ele: "Como pudera o autor alcançar conhecimentos idênticos aos do médico - ou pelo menos comportar-se como se os possuísse?" (p. 55). Torna-se, do ponto de vista psicanalítico, cada vez mais clara e pertinente a aproximação entre a verdade e a ficção.

A seguir, Freud retorna às análises do herói do romance tal como se este fosse um analisando. Desta vez, arrisca realizar "diagnósticos" à luz de sua teoria; considera os delírios da personagem (o próprio autor de Gradiva chama de delírios o fato de Norbert tomar sua amiga esquecida de infância por um fantasma), e recorre à literatura científica para demonstrar que delírio, no sentido médico do termo, é um conjunto de perturbações psíquicas patológicas que não incidem sobre corpo físico, caracterizado, também, pela primazia das "fantasias". Contudo, ao continuar seu raciocínio, lembra do fato que levou Norbert a viajar para Pompeia: seu fascínio sobre a posição dos pés em que se encontrava a escultura por ele chamada de Gradiva. Alega que talvez, um psiquiatra realizaria um grosseiro (o mesmo termo utilizado pelo próprio Freud) diagnóstico a respeito deste fato, classificando o herói como um "fetichista" paranoico. Entretanto, ele vai adiante. Além de considerar os sistemas de nomenclaturas médicas "precárias e estéreis" (p. 48), ele acredita que o caso do arqueólogo seria mais corretamente descrito como uma histeria e não como um delírio paranoico. Sabe-se que a ideia de histeria nos homens era algo relativamente recente e não totalmente bem aceito.

Neste momento, podemos identificar uma "sinalização" dos caminhos da teoria psicanalítica sobre a histeria. Na verdade, como vimos, Freud rapidamente menciona algo associado à histeria nos seus escritos sobre a Gradiva de Jensen. Mas ele também nos fala sobre a ideia de delírio (do neurótico), algo que será mencionado, sobretudo, no quarto capítulo de seu texto. Quando ele nos diz da revelação de Zoe para Hanold de que, na verdade, ela é sua amiga de infância há muito por ele esquecida, Freud não cessou em continuar a interpretar a história, seus elementos e os possíveis mecanismos substitutivos que aparecem nos sonhos de Hanold.

$\mathrm{O}$ autor estabelece assim uma íntima ligação entre o desvanecimento do delírio e o ressurgimento da ânsia de amar, preparando o caminho para o inevitável desenlace amoroso. Ele conhece a natureza básica do delírio melhor do que seus críticos: sabe que o mesmo resultou da combinação de um componente do desejo amoroso com a resistência a esse desejo, e deixa que a jovem encarregada da cura se aperceba do elemento que lhe é convenientemente agradável. Foi somente este conhecimento que fez com que ela se decidisse dedicar-se ao "tratamento"; foi somente a certeza de ser amada pelo jovem que a induziu a confessar-lhe o seu amor. O tratamento consistiu em dar-lhe acesso, pelo exterior, às lembranças reprimidas que ele não conseguia atingir no seu interior; contudo o mesmo frustrar-se-ia no seu decorrer se a "analista" não houvesse levado em conta os sentimentos dele, e se sua tradução final do delírio não houvesse sido a seguinte: "Olha, tudo isso significa apenas que me amas" (Freud, 1907 p. 81).

Além disso, a ideia de fetichismo que ele menciona e propõe é de cunho totalmente psicanalítico (e não psiquiátrico), afirmando que o autor está em acordo com a (sua) ciência ao relacionar as impressões fetichistas do herói com algo associado à infância. Freud menciona que esta ideia foi primeiramente debatida por Binet em 1888, 
mas ele mesmo a discutiu em seus Três ensaios sobre a teoria da sexualidade (1905), publicada dois anos antes da publicação de Delírios e sonhos na Gradiva de Jensen. Mais uma vez, a obra do alemão parece confirmar (convenientemente) muitas das ideias novas que Freud elaborava, e que daria corpo à teoria que hoje é conhecida como psicanálise. Cronologicamente falando, a análise de Gradiva situa-se justamente no ponto em que a teoria de Freud acabara de lançar os pilares mais básicos e mais importantes que sustentariam um novo constructo que, naquele momento, estava dando seus primeiros (mas já não tão tímidos) passos.

O conceito freudiano de inconsciente também teve lugar na análise do conto de Jensen (inclusive sendo relacionado diretamente ao conceito de recalque). Freud expressou ainda que gostaria que seu conceito de inconsciente não fosse objeto de discussões de filósofos e naturalistas, alegando que os mesmos só lhe dão importância etimológica. Inconsciente, para a psicanálise, é algo muito mais amplo. Tão mais amplo que seus mecanismos não teriam apenas o objetivo de transportar os seus conteúdos para o nível da consciência.

Neste momento do seu escrito, ainda durante a análise do primeiro sonho de Hanold, Freud realiza mais uma observação, que é justamente, também, um dos preceitos básicos de sua teoria: "Os sonhos e os delírios surgem de uma mesma fonte - do que é reprimido. Poderíamos dizer que os sonhos são os delírios fisiológicos das pessoas normais" (Freud, 1907 p. 61). Na verdade, esta afirmação diz respeito à mesma ideia mencionada anteriormente, de que os limites entre o que é considerado como normal e o que é tido como doença não distam. $\mathrm{E}$ assim, seus apontamentos feitos através da sua árdua análise do primeiro sonho concluem o segundo capítulo de sua obra.

Freud inicia o terceiro capítulo com uma pequena análise do segundo sonho de Norbert Hanold, apontando ali o mecanismo de defesa inconsciente que o fazia rechaçar seu erotismo infantil recalcado: o repúdio aos casais que estavam próximos a ele. Sua repulsa implicaria, para o psicanalista, em um mascaramento do desejo sexual, traço típico na neurose, também sinalizado no seu repúdio às moscas presentes em Pompeia e seu ato de acasalamento (comparando as mesmas aos casais apaixonados anteriormente vistos). Do mesmo modo, Hanold havia "esquecido" seu amor infantil por Zoe. Aqui vemos, novamente, o conceito de recalque sendo sinalizado por Freud.

Para a análise do segundo sonho, Freud utilizou a mesma técnica empregada para a análise de sonhos em A Interpretação dos Sonhos. Vejamos: "Podemos aplicar a esse sonho uma técnica que constitui o procedimento normal para a interpretação dos sonhos. Consiste em não prestar atenção nas conexões aparentes no sonho manifesto, mas em concentrar a atenção isoladamente em cada um dos elementos do seu conteúdo, buscando sua origem nas impressões, lembranças, e associações livres do sonhador"' (Freud, 1907 p. 69).

Freud explica, sem pestanejar, toda a análise do segundo sonho de Hanold através de sua teoria sobre a interpretação de sonhos, citando seus mecanismos e inserindo-os como se a personagem fosse, de fato, uma pessoa que fizesse parte da realidade empírica. A máxima freudiana de que podemos, por vezes, tomar personagens literários como pessoas que vivem no mundo da não-ficção é, aqui, explicitamente usada.

Relembremos que o artista retira elementos da realidade e deles se utiliza para recria-la, como vimos anteriormente. Deste modo, faz sentido essa aproximação da qual fala Freud entre personagens fictícios e pessoas reais.

Após uma extensa exposição do segundo sonho e com sua análise detalhada concluída, Freud finaliza a construção de seu raciocínio de modo simples. O que nos parece é que, ao final, ele definiu de forma (deve-se enfatizar) deveras resumida o preceito da psicanálise: "Fomos capazes de compreender tanto este como o sonho anterior apoiando-nos na pressuposição de que o sonhador sabe, em seus pensamentos inconscientes, de tudo aquilo que esqueceu em seus pensamentos conscientes, e de que nos primeiros avalia corretamente o que nos últimos transforma em delírio" (Freud, 1907 p. 77). 
No quarto e último capítulo de sua análise, Freud fala do processo de "cura", conduzido por Zoe-Gradiva (da qual ele, como foi dito, faz equivaler como "médica" do "paciente" Norbert Hanold) sobre o herói do romance. Novamente, as personagens da ficção são faladas como seres da realidade.

Do ponto de vista da teoria psicanalítica, primeiramente, Freud define no que consistiu o tratamento realizado pela heroína. Segundo ele, este foi efetuado através do acesso dado ao arqueólogo das lembranças recalcadas, sem deixar de levar em consideração os seus sentimentos e o estado "delirante" em que se encontrava.

Neste ponto, vemos novamente o lugar de analista que Freud delega à personagem Zoe, explicando detalhadamente como havia sido o "tratamento" realizado por ela em Hanold: trazendo à tona seus esquecimentos, realizando a "cura do delírio". Enquanto isso, Freud demonstra que tal método de tratamento era exatamente o mesmo que era conhecido como o método "catártico", empregado por Breuer alguns anos antes (1893-1895), ao qual ele havia se dedicado, preferindo chamá-lo de "psicanalítico". Seu objetivo era o de fazer com que pacientes com delírios semelhantes aos de Hanold adquirissem consciência de elementos recalcados no inconsciente.

Aqui somos capazes de identificar, a partir do que foi retirado do texto para ser usado para demonstração, outros conceitos da psicanálise presentes nos escritos de Freud, como o conceito de transferência e de recalque.

Ao falar sobre o método terapêutico empregado por Breuer (e que por Freud foi aperfeiçoado), e utilizado por Zoe, remetemo-nos ao conceito de transferência. Quando Freud diz que a cura só foi possível porque a heroína levou em conta os sentimentos de Hanold, não classificando seus acessos delirantes como loucura, ou como algo patológico, podemos constatar que este mesmo fator que devolveu a "sanidade" ao arqueólogo foi possível devido ao processo transferencial. E a transferência, como sabemos, é um mecanismo que foi "descoberto" nos primórdios da formulação teórica de psicanálise, nos Estudos sobre a Histeria (Breuer; Freud, 1893-1895), quando Breuer percebeu que sua paciente, Anna O., mantinha um "vínculo" com ele, seu médico, de modo que isso o auxiliava no processo de cura. Portanto, só através de estabelecida a transferência entre Hanold e sua amiga é que pôde ser possível o processo pelo qual o arqueólogo foi despertado de seu delírio apaixonado.

Outro conceito psicanalítico será delineado, no último capítulo da análise freudiana: o conceito de pulsão. Neste caso, ele será apenas insinuado: "Mas a semelhança entre o processo empregado por Gradiva e o método analítico de psicoterapia não se limita a esses dois aspectos - tornar consciente o que foi reprimido e fazer coincidir o esclarecimento e a cura. Estende-se também ao que consideramos o ponto fundamental de toda a modificação: o despertar dos sentimentos. Toda perturbação semelhante ao delírio de Hanold, o que em termos científicos chamamos habitualmente "psiconeurose", tem como precondição a repressão de uma parcela da vida instintual ou, já podemos afirmar, do instinto sexual” (Freud, 1907 p. 82).

E assim, Freud finaliza sua primeira análise completa de uma obra artística. Depois de afirmar que o processo de cura do tratamento psicanalítico do "paciente" Norbert Hanold consiste em "libertar o amor reprimido que na conciliação de um sintoma encontrara escoamento insuficiente" (Freud, 1907 p. 82). Freud conclui que Zoe Bertgang é uma lembrança recalcada da infância do arqueólogo Norbert Hanold, que foi despertada quando este viu uma gravura em baixo relevo de uma jovem que aparentava ser de andar gracioso. A partir daí, toda uma trama de acontecimentos foi criativamente tecida pelo autor e que despertou, naquele momento, a atenção de Freud através de Jung. 


\section{Conclusão}

É interessante observar que, a partir daí, notamos uma herança deixada por Freud aos seus seguidores no que concerne ao fato de haver uma procura, ou melhor, uma curiosidade sobre elementos presentes nas obras artísticas para explicitar conceitos psicanalíticos.

Durante sua narrativa, Freud não cessou em interpretar a história, seus elementos e os possíveis mecanismos substitutivos que aparecem nos sonhos da personagem Hanold. Era quase como se o romance tivesse sido escrito para propositalmente fazer com que alguns conceitos psicanalíticos fossem bem expostos, para um melhor entendimento. A impressão deixada por Freud ao longo de todo o seu texto é de que ele pôs o protagonista do romance num divã e "escavou" seu inconsciente (alusão feita por alguns autores à paixão que Freud tinha pela arqueologia, relacionando-a com o interesse pela Gradiva), trazendo à tona elementos que, acima de tudo, nos colocam frente a frente com alguns dos principais conceitos de sua teoria (fantasia, recalque, etc.).

Contudo, o próprio Freud nos alertou neste mesmo escrito de que se deve tomar cuidado ao realizar essa tarefa, pois "é fácil vermos em toda parte aquilo que se procura e que está ocupando a nossa mente" (Freud, 1907 p. 83). Dito isto, portanto, fica claro que o psicanalista jamais teve a intenção de se utilizar da literatura como uma maneira de justificar sua teoria ou em busca de adeptos. Freud enviou a análise de Gradiva a Jensen, e este, tendo apreciado o gesto, concordou com grande parte das análises empregadas por ele, porém deixando claro que desconhecia os conceitos da psicanálise ali presentes, e afirmando, também, que escrevera a obra por puro prazer, advinda de sua veia criativa, sem inspirações buscadas em outros campos teóricos (mais precisamente, os científicos). E é justamente aí que reside a relação entre a arte literária e a psicanálise que procuramos demonstrar neste trabalho, e que Freud já sabia desde o início, jamais sendo leviano nem se utilizando da literatura meramente para justificar suas formulações teóricas.

\section{Referências}

BRANDÃO, Ruth Silviano. Literatura e psicanálise. Porto Alegre: Editora da Universidade/UFRGS, p. 13-39, 1996.

BREUER, Josef; FREUD, Sigmund. Estudos sobre histeria (1893-1895).

Obras Completas de Sigmund Freud. Rio de Janeiro: Imago, v. 2, 1976. . Edição Standard Brasileira das

FREUD, Sigmund. A interpretação dos sonhos. L\&PM Ed., 2012.

FREUD, Sigmund. Algumas considerações para um estudo comparativo das paralisias motoras orgânicas e histéricas (1893 [1888-1893]). FREUD, Sigmund. Edição Standard brasileira das obras psicológicas completas de Sigmund Freud. Rio de Janeiro: Imago, v. 1, p. 223-245, 1987

FREUD, Sigmund. Delírios e sonhos na Gradiva de Jensen (1906-1907).Obras psicológicas completas de Sigmund Freud: edição standart brasileira, v. 9.

FREUD, Sigmund. Escritores criativos e devaneios. Edição standard brasileira das obras psicológicas completas, v. 9, 1908.

FREUD, Sigmund. O Estranho (1919). ESB. Obras completas, 1969. 
FREUD, Sigmund. Os chistes e sua relação com o inconsciente. Imago, 1977.

FREUD, Sigmund. Romances familiares. Edição Standard Brasileira das Obras Psicológicas Completas de Sigmund Freud, v. 9, 1909.

FREUD, Sigmund. Sobre os sonhos. Edição Standard Brasileira das Obras Completas de S. Freud, v. 5, 1901.

JENSEN, Wilhelm. Gradiva: una fantasia pompeiana. Donzelli, 2013.

RIVERA, Tânia. Arte e psicanálise. Zahar, 2005.

TEIXEIRA, Leônia Cavalcante. Eros adormecido: violência e laço social na interface entre literatura e psicanálise. 2001. Tese de Doutorado. Universidade do Estado do Rio de Janeiro. Instituto de Medicina Social.

Recebido: 26/02/2015

Aceito: 09/03/2015 